\title{
INFLUÊNCIA DA PRECIPITAÇÃO NA TURBIDEZ DAS ÁGUAS DOS RIOS CUBATÃO DO SUL E VARGEM DO BRAÇO/SC: UMA ANÁLISE PARA GESTÃO DE ESTAÇÃO DE TRATAMENTO DE ÁGUA
}

Resumo: A região da Grande Florianópolis registra uma tendência de aumento gradativo no consumo de água. Somente a cidade de Florianópolis teve um aumento populacional de aproximadamente $15 \%$ nos últimos 10 anos, o que representa um aumento no consumo de cerca de 10 milhões de litros de água por dia. Atualmente são potabilizados uma média de 259 milhões de litros de água por dia na Estação de Tratamento de Água (ETA) José Pedro Horstmann. As águas dos rios Cubatão do Sul e Vargem do Braço são responsáveis pelo abastecimento de aproximadamente 700 mil pessoas, nos municípios de Florianópolis, São José, Palhoça, Biguaçu e Santo Amaro da Imperatriz. Diante da importância desses mananciais para uma parcela considerável da população de Santa Catarina, este trabalho verificou, por meio de análises estatísticas, se a variável precipitação é um bom preditor da turbidez da mistura das águas dos dois rios, com indicação de uso no planejamento e gerenciamento da ETA. Concluiu-se que a precipitação explica apenas $10 \%$ da turbidez, o que indica que existem outras variáveis com influência neste parâmetro e consequentemente na qualidade da água bruta desses rios.

Palavras-Chave: Bacia Hidrográfica. Qualidade da água. Abastecimento público.

\section{INFLUENCE OF PRECIPITATION ON THE TURBIDITY OF RIVER WATERS CUBATÃO DO SUL AND VARGEM DO BRAÇO/SC: AN ANALYSIS FOR MANAGEMENT OF WATER TREATMENT PLANT}

\begin{abstract}
The Grande Florianópolis Region has had an increasing in the potable water consumption. In the last 10 years, only Florianópolis city had a population increases of approximately 15\%. It represents a consumption increases of about 10 million liters of water per day. At the José Pedro Horstmann Water Treatment Plant, 259 million liters of water are currently being potabilized per day. The water come from the Cubatão do Sul and Vargem do Braço rivers, supplying approximately 700 thousand people in the municipalities of Florianópolis, São José, Palhoça, Biguaçu and Santo Amaro da Imperatriz. These rivers impact a considerable part of Santa Catarina population and are mixed to use as raw water at the Water Treatment Plant. This work verified, through statistical analysis, if the precipitation variable is a good predictor of turbidity when measured at the water coming from the two rivers mixed. Also, the research discussed if precipitation could be considered as an indicator to planning and management of Water Treatment Plant. It was concluded that the precipitation explains only $10 \%$ of the turbidity, which indicates that there are other variables with influence in this parameter and consequently in the raw water quality of the rivers studied.
\end{abstract}

Keywords: Hydrographic Basin. Water quality. Public supply.

\footnotetext{
1 Instituto Federal de Santa Catarina - IFSC, Departamento Acadêmico de Saúde e Serviços, Florianópolis, Brasil, juhloch@gmail.com, https://orcid.org/0000-0002-8073-4105

2 Instituto Federal de Santa Catarina - IFSC, Departamento Acadêmico de Saúde e Serviços, Florianópolis, Brasil, brentano@ifsc.edu.br, https://orcid.org/0000-0002-9649-6439
} 


\section{INFLUENCIA DE LA PRECIPITACIÓN EM LA TURBIDEZ DE LAS AGUAS DE LOS RIOS CUBATÃO DO SUL Y VARGEM DO BRAÇO: UN ANÁLISIS PARA LOS GESTIÓN DE ESTACIÓN DE TRATAMIENTO DE AGUA}

Resumen: La región de la Grande Florianópolis registra una tendencia de aumento gradual en el consumo de agua. Sólo la ciudad de Florianópolis tuvo un aumento poblacional de aproximadamente $15 \%$ en los últimos 10 años, lo que representa un aumento en el consumo de cerca de 10 millones de litros de agua al día. Actualmente son potabilizados una media de 259 millones de litros de agua al día en la Estación de Tratamiento de Agua José Pedro Horstmann. Las aguas de los ríos Cubatão do Sul y Vargem do Braço son responsables del abastecimiento de aproximadamente 700 mil personas, en los municipios de Florianópolis, São José, Palhoça, Biguaçu y Santo Amaro da Imperatriz. En cuanto a la importancia de estos manantiales para una parte considerable de la población de Santa Catarina, este trabajo verificó, através de análisis estadísticos, si la variable precipitación es un buen predictor de la turbidez de la mezcla de las aguas de los dos ríos, con indicación de uso en la planificación y gestión de la Estación de Tratamiento de Agua. Se concluyó que la precipitación explica sólo el $10 \%$ de la turbidez, lo que indica que existen otras variables con influencia en este parámetro y consecuentemente en la calidad del agua bruta de esos ríos.

Palabras clave: Cuenca Hidrográfica. Calidad del agua. Abastecimiento público.

\section{Introdução}

O acesso à água potável está cada dia mais comprometido pelo aumento do consumo de recursos naturais e da poluição, colocando em cheque as políticas de abastecimento e a disponibilidade desse recurso para todos, de forma igualitária.

No sul do Brasil, no Estado de Santa Catarina, as águas do rio Cubatão do Sul e rio Vargem do Braço são responsáveis pelo abastecimento de aproximadamente 700 mil pessoas (CASAN, 2013), quase 10\% da população total do Estado de Santa Catarina, residentes nos municípios de Florianópolis, São José, Palhoça, Biguaçu e Santo Amaro da Imperatriz.

A turbidez das águas é um importante indicador da qualidade ambiental de um rio. De acordo com a ANA (2018) a turbidez indica o grau de atenuação que um feixe de luz sofre ao atravessar a água. Esta atenuação ocorre pela absorção e espalhamento da luz causada pelos sólidos em suspensão (silte, areia, argila, algas, detritos, etc). O tipo de tratamento de água realizado pela Companhia Catarinense de Águas e Saneamento (CASAN), na Estação de Tratamento de Água (ETA) José Pedro Horstmann - também é conhecida como ETA Morro dos Quadros ou ETA Cubatão - teve que ser alterado de filtração direta ascendente para ciclo completo devido à piora na qualidade da água recebida na ETA ao longo dos últimos 20 anos, principalmente alterações negativas na cor e na turbidez das águas. $O$ aumento populacional e maior ocupação nas áreas adjacentes aos cursos d'águas neste 
período pode ter promovido a piora na qualidade. Com relação a algumas cidades influentes na Bacia Hidrográfica, de acordo com os Censos do IBGE, do ano de 1991 ao ano de 2010, a cidade de Águas Mornas teve aumento populacional de $16 \%$, Santo Amaro da Imperatriz teve aumento populacional de 33\% e Palhoça teve aumento de $50 \%$ na população.

Devido ao aumento da demanda de consumo hídrico, as alterações ocorridas na qualidade da água recebida, e a maior exigência nos limites estabelecidos pelas legislações do Ministério da Saúde, a ETA passou por um processo de ampliação e reforma se tornando uma ETA convencional e recebendo novas etapas no tratamento da água, como a floculação e a decantação (etapas antes desnecessárias, pois a água era de boa qualidade), visando aumento da vazão e melhoria na qualidade da água distribuída.

A hipótese deste trabalho é de que existe uma relação direta entre a precipitação e a turbidez da mistura das águas dos rios utilizados para abastecimento. Para testar essa hipótese foram avaliados 20 anos de dados de precipitação e turbidez e foi verificado se a variável precipitação é um bom preditor da turbidez da mistura das águas dos rios Cubatão do Sul e Vargem do Braço, com indicação de uso no planejamento e gerenciamento da ETA José Pedro Horstmann.

\section{Material e métodos}

A Bacia Hidrográfica do Rio Cubatão (Figura 01), está localizada entre as coordenadas $27^{\circ} 35^{\prime} 46^{\prime \prime}$ e $27^{\circ} 52^{\prime} 50^{\prime \prime}$ S e $48^{\circ} 38^{\prime} 24^{\prime \prime}$ e $49^{\circ} 02^{\prime} 24^{\prime \prime} \mathrm{W}$, a oeste de Florianópolis, na porção continental do Estado de Santa Catarina. Os municípios que estão contidos na área de drenagem da referida Bacia são: Águas Mornas, Santo Amaro da Imperatriz, parte de São Pedro de Alcântara e Palhoça (CASAN, 2003). 
Figura 01 - Localização da Bacia Hidrográfica do Rio Cubatão do Sul

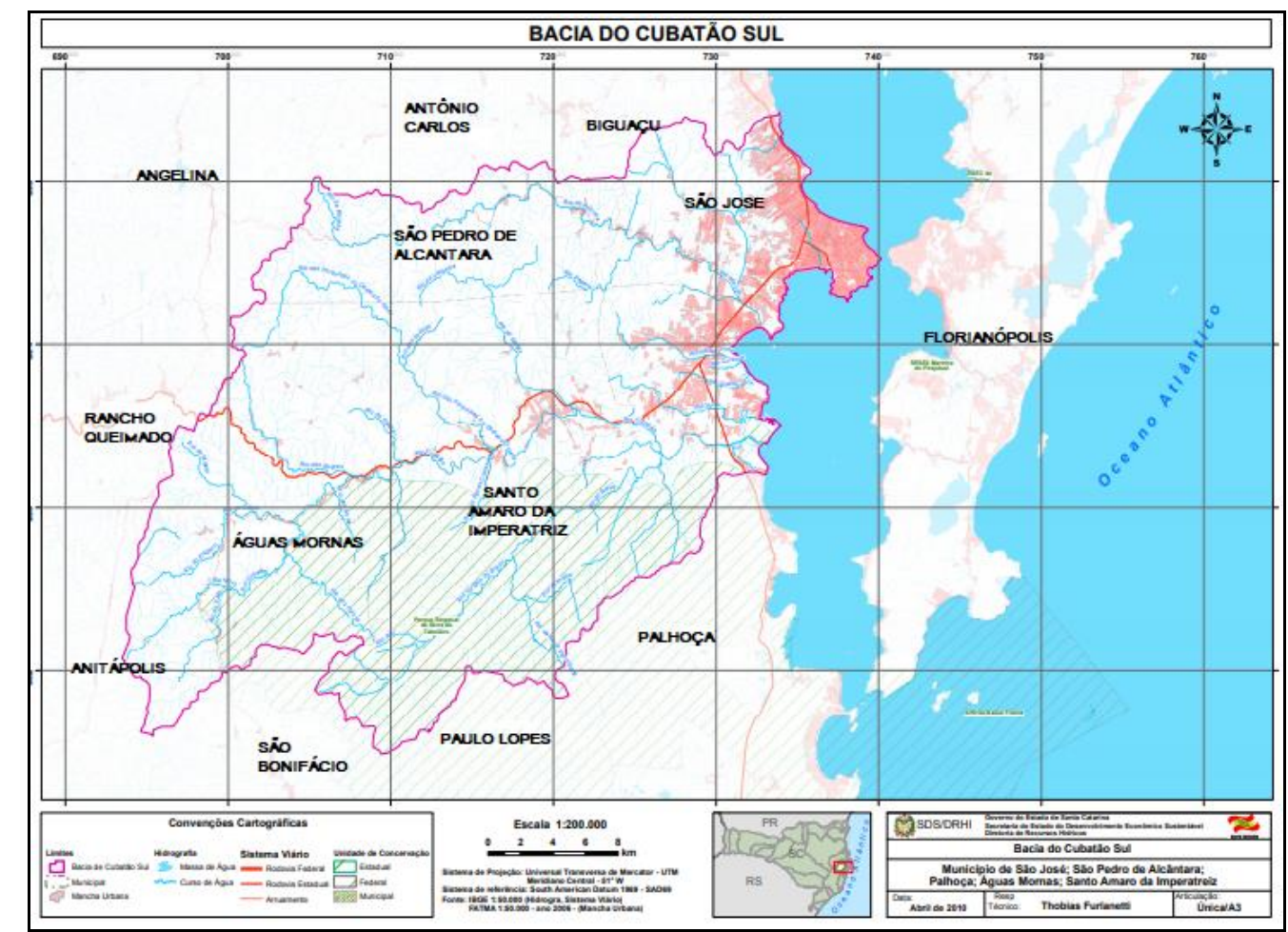

Fonte: SDS/DRHI, 2010.

A Bacia possui uma área de drenagem igual a $738 \mathrm{~km}^{2}$ e seu principal afluente é o rio Cubatão do Sul, originado da união entre o rio Cedro e o rio Bugres, no município de São Bonifácio. A sua extensão é de $65 \mathrm{~km}$. O rio Cubatão do Sul, juntamente com o rio Vargem do Braço é utilizado para captação de água para abastecimento da população de cinco municípios.

Alguns dos usos da terra da bacia hidrográfica são a agricultura do tipo familiar, o turismo hoteleiro com disponibilização de águas termais, que possui propriedades terapêuticas; atividades de recreação e lazer exercidas pelos visitantes e moradores, como a prática de esportes de aventura, exemplo o raffting. Além disso, há na área industrialização de água mineral, ocupação residencial, atividades econômicas como indústrias, comércio e extração de areia. Esta última atividade pode ser uma das principais origens de sedimentos nas águas da Bacia.

Quanto à vegetação, Exterckoter (2006) afirma que a bacia possui cinco diferentes formações, todas no domínio da mata atlântica: Vegetação Litorânea (manguezais e restingas), Floresta Atlântica ou Floresta Ombrófila Densa, Floresta de Araucária ou Floresta Ombrófila Mista, Matinha Nebular e Campos de Altitude. Ainda segundo Exterckoter (2006) nas encostas do curso médio e superior do rio Cubatão do Sul e seus afluentes, se forma o ecossistema de Floresta Atlântica (Floresta Ombrófila Densa). Nas partes mais altas das encostas aparecem, em meio 
à mata atlântica, as araucárias, e por isso esse ecossistema passa a chamar-se Floresta Ombrófila Mista.

Nas nascentes do Rio Cubatão do Sul, principalmente nas partes mais altas do Parque Estadual da Serra do Tabuleiro, formam-se os ecossistemas de Matinha Nebular e Campos de Altitude, em altitudes superiores a 1200 m. Curtarelli (2009) conclui que a bacia possui $50 \%$ de suas terras acima da cota 490 metros, tendo uma altitude máxima de 1260 metros e altitude mínima de 0 metros. Também que as características de declividade da bacia indicam que $49,92 \%$ da área da bacia possui terreno ondulado.

Uma das principais características da bacia hidrográfica é que a mesma se encontra em grande parte, dentro dos limites do Parque Estadual da Serra do Tabuleiro (PEST), devendo a isto, as áreas preservadas que ainda existem na região.

O extrativismo vegetal praticado na área da bacia vem acarretando danos ao ecossistema e consequentemente à hidrografia. Com relação específica ao rio Cubatão do Sul, a retirada da mata ciliar, o despejo de esgoto doméstico, a extração de areia e a agricultura vêm gradativamente degradando tanto as margens como a qualidade e quantidade de suas águas (CASAN, 2003).

\section{Dados de turbidez}

Os dados de turbidez utilizados neste trabalho compreendem o acervo da ETA José Pedro Horstmann - CASAN. Os resultados das análises de turbidez, realizados de duas em duas horas, estavam em arquivos físicos da CASAN, ou seja, as informações estavam planilhadas em papel. Para este trabalho, os dados de turbidez da mistura da água bruta dos rios Cubatão do Sul e Vargem do Braço foram digitados em planilhas do Excel juntamente com os dados que já estavam em meios digitais e organizados para se trabalhar estatisticamente. Trabalhou-se com a média diária de turbidez dos últimos 20 anos.

\section{Dados de precipitação}

Os dados de precipitação de 20 anos foram obtidos no Sistema de Informações Hidrológicas (HIDROWEB) da ANA (Agência Nacional das Águas). A estação utilizada foi a de Código: 2748004, localizada dentro da Bacia Hidrográfica em estudo, no município de Palhoça, (Figura 02). Esta é a estação que está mais próxima da ETA e segundo Pereira et. al. (2013), em uma análise de variâncias pluviométricas nas estações localizadas na região da bacia hidrográfica do rio 
Cubatão do Sul, demonstrou em seus resultados que ocorre uma semelhança entre as distribuições da variância da série histórica analisada por ele e que também ocorre uma similaridade entre as médias pluviométricas das estações com um número relativamente baixo de eventos extremos.

$\mathrm{Na}$ figura 02 estão localizados os rios Cubatão do Sul em azul escuro e Vargem do Braço em azul claro, também podemos verificar onde estão localizadas as captações dos dois rios, a localização da estação meteorológica da ANA e bem próxima a ETA José Pedro Horstmann.

Figura 02 - Localização das captações de água dos rios, da ETA e da Estação da ANA

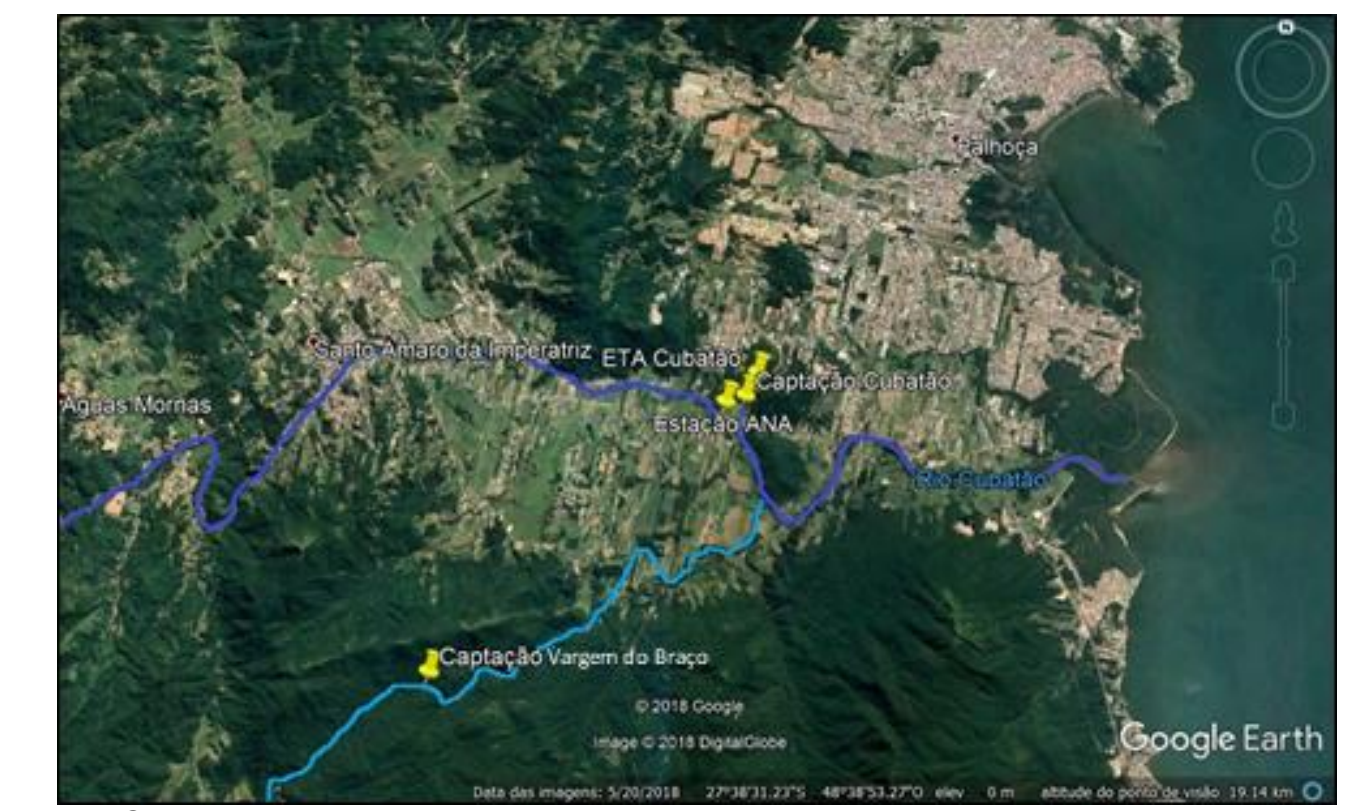

Fonte: Google Earth, 2018.

\section{Análises estatísticas}

Foram utilizados o aplicativo Microsoft Excel para elaboração de tabelas e gráficos, além das análises simples de correlação. Para as regressões lineares foi utilizado o software Statistica e o software Minitab.

Visando compreender o poder explicativo da precipitação na variação da turbidez da mistura da água dos rios Cubatão do Sul e Vargem do Braço, antes da sua entrada na ETA José Pedro Horstmann, realizou-se uma análise de regressão $(\alpha=0,05)$. Removeram-se dados faltantes e trabalhou-se com $n=3965$, compreendendo dados diários do período de 10 anos, entre 2007 a 2017. Decidiu-se trabalhar com este período, diante da observação de que houve uma provável mudança de metodologia na medição de turbidez que provocou uma visível discrepância entre os dados a partir de 2005. 
A distribuição dos dados foi verificada e os mesmos foram transformados utilizando a função logarítmica para ajustarem-se à distribuição normal. Testou-se a influência da precipitação sobre a variação da turbidez no dia do evento climático, um dia após o evento e dois dias após o evento.

\section{Resultados e discussão}

\section{Precipitação}

A precipitação na bacia hidrográfica do rio Cubatão do Sul representa o clima característico do Estado, onde as estações quentes são as mais chuvosas e as estações frias são as que apresentam menores índices de precipitação.

Na média histórica, compreendida entre os anos de 1997 e 2017, o mês mais chuvoso na região da bacia hidrográfica do rio Cubatão do Sul foi o mês de janeiro, com média de precipitação de 251,81 mm, seguido de fevereiro com 216,36 mm, março com 200,41 mm e dezembro com 198,44 mm, todos meses de verão.

No tempo estável, recorrente nos meses de inverno, é onde se encontram os menores valores de precipitação na bacia, sendo junho o mês menos chuvoso, com média de $88,91 \mathrm{~mm}$ de precipitação. Em tempos de estiagem severa, os rios da região baixam consideravelmente sua vazão, podendo causar problemas para o abastecimento de água.

O ano de 2008 teve a maior precipitação dos últimos 20 anos, 3.070,6 mm, com os anos seguintes ainda apresentando valores elevados. O valor médio de precipitação anual no período compreendido entre 1997 a 2017, na bacia hidrográfica foi de $1.954 \mathrm{~mm}$.

Existe uma tendência no aumento da precipitação na bacia hidrográfica do rio Cubatão do Sul, assim como verificado por Gotardo (2018), que concluiu em seu trabalho que, é possível afirmar que existe um aumento das precipitações no Estado de Santa Catarina, e que para as regiões Leste existe tendência de um aumento de 10,5\% para os próximos 20 anos. Foi encontrado, na série histórica analisada, um aumento médio de 18\% nos valores de precipitação da primeira década (1997 a 2007) para a segunda década (2007 a 2017).

No ano de 2008, ocorreu uma elevação na média de precipitação. De acordo com Dias (2009) o evento ocorrido em Santa Catarina neste ano proporcionou uma elevada quantidade de chuva, que devido à sua continuidade ocasionou enchentes e diversos deslizamentos sobre as encostas. Os dias que apresentaram a maior precipitação estão compreendidos entre 20 e 24 de novembro de 2008. Ainda 
segundo o autor não há registro de um novembro tão chuvoso nas regiões da Grande Florianópolis, Vale do Itajaí e Litoral Norte como observado em 2008, quando diversos recordes históricos foram quebrados.

\section{Turbidez}

O mês com maiores médias de turbidez, na bacia hidrográfica do rio Cubatão do Sul, foi fevereiro de 2002 (59,89 NTU de turbidez) e o mês com menor média de turbidez foi junho de 2008 (0,92 NTU de turbidez) valor muito inferior ao encontrado no mês de fevereiro. As menores médias de turbidez estão compreendidas nos meses de inverno, final de junho, julho e agosto. Gonçalves et al. (2012) também constataram em seu trabalho a alteração sazonal no nível de turbidez, entre as estações chuvosa e seca, que no caso do Estado de Santa Catarina coincidem com verão e inverno, respectivamente.

Na média, o ano com maior turbidez foi 2002 (34,72 NTU) e o ano com a menor média de turbidez foi 2005 (2,00 NTU). No estudo de Raposo, et al. (2009), em outro rio, a alteração dos níveis de turbidez foi correlacionada com o uso do solo na bacia hidrográfica.

Sobre as causas da turbidez, Raposo et al (2009) cita que um dos principais parâmetros de qualidade das águas capaz de demonstrar alterações na dinâmica hidrossedimentar de uma bacia como consequência da erosão acelerada é a turbidez. Esta indica o nível de interferência que a luz sofre ao passar pela água e, dessa forma, expressa a quantidade de material em suspensão, podendo ser usada como uma medida direta dessa quantidade. Os sólidos em suspensão na água podem ser de origem natural (partículas de rochas, argila, silte, algas e outros microorganismos) ou antrópica (lançamento de efluentes não tratados, práticas agrícolas inadequadas, retirada da mata ciliar, extração de areia, dentre outros).

De 2007 a 2012 a turbidez média se manteve menor que 5 NTU, com um pico na média de turbidez no ano de 2012 (7,81 NTU). Em 2013 houve uma queda na média de turbidez e nos anos seguintes o parâmetro seguiu um aumento gradativo, até o maior valor médio encontrado de turbidez, no ano de 2017, com média de 16,16 NTU. Houve um aumento nas médias de turbidez de 56\% (2007 a 2017), indicando aumento da turbidez na mistura das águas dos rios Cubatão do Sul e Vargem do Braço nos últimos dez anos. 


\section{Relação entre turbidez e precipitação}

De acordo com Penedo (2015) a turbidez da água em um ponto é influenciada pelas características da bacia a montante. A precipitação é o fator mais importante na geração de turbidez de origem difusa em bacias rurais, por sua ação mecânica na desagregação, deslocamento e carreamento das partículas de solo. Contudo, a interação da precipitação com a superfície é influenciada pela cobertura vegetal, pelas características do solo e conformação do terreno, elementos que modelam a trajetória da água entre os processos de interceptação, infiltração e escoamento superficial.

Para Delpla et al. (2009) a mudança climática não é o único fator que afeta a qualidade da água. Integrado ao conceito de mudança global, evolução do uso da terra, o desmatamento, o espalhamento urbano e a impermeabilização de áreas também contribuem para a degradação da qualidade da água. Mas mais frequentemente, a poluição da água está diretamente ligada às atividades humanas de desenvolvimento urbano, industrial ou agrícola.

Na Figura 03 foram relacionadas as médias anuais de precipitação e turbidez, onde fica evidente como as duas variáveis não interagem. Os dados de precipitação foram divididos por 100 para deixar as relações entre ambos mais visíveis no gráfico.

Figura 03 - Médias anuais de precipitação $(\mathrm{mm})$ (a precipitação foi dividida por 100) e turbidez (NTU) na BH do rio Cubatão do Sul (2007 a 2017)

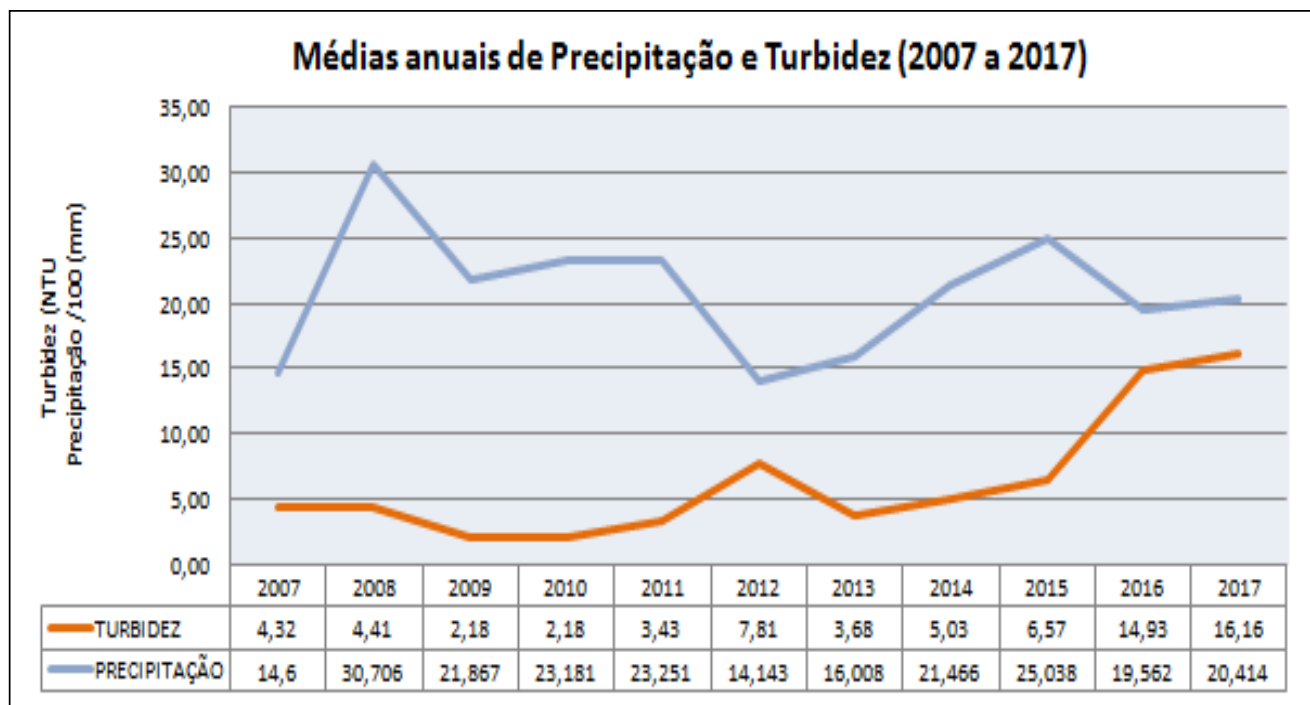

Fonte: Elaborado pelas autoras.

É possível visualizar que, no conjunto de dados analisados, não se observou tendência entre precipitação e turbidez na série, pois aparecem períodos com alta precipitação e baixa turbidez e períodos com alta turbidez e queda na precipitação. 
A precipitação apresenta uma influência muito pequena sobre a turbidez na mistura da água dos rios Cubatão do Sul e Vargem do Braço, antes da entrada na ETA José Pedro Horstmann, quando se considera o dia do evento climático $\left(R^{2}=0,02 ; p<0,05\right)$. Contudo, após um dia da precipitação observada, a precipitação explica $10 \%$ da variação dos dados de turbidez no sistema $\left(R^{2}=0,10 ; p<0,05\right)$ (Figura 04). Esta influência volta a diminuir após dois dias da ocorrência da precipitação $\left(R^{2}=0,02 ; p<0,05\right)$.

Figura 04 - Variação da Turbidez (NTU) em função da Precipitação $(\mathrm{mm})$ na mistura da água dos rios Cubatão do Sul e Vargem do Braço, antes da entrada na ETA José Pedro Horstmann $(R 2=0,10 ; p<0,05)$

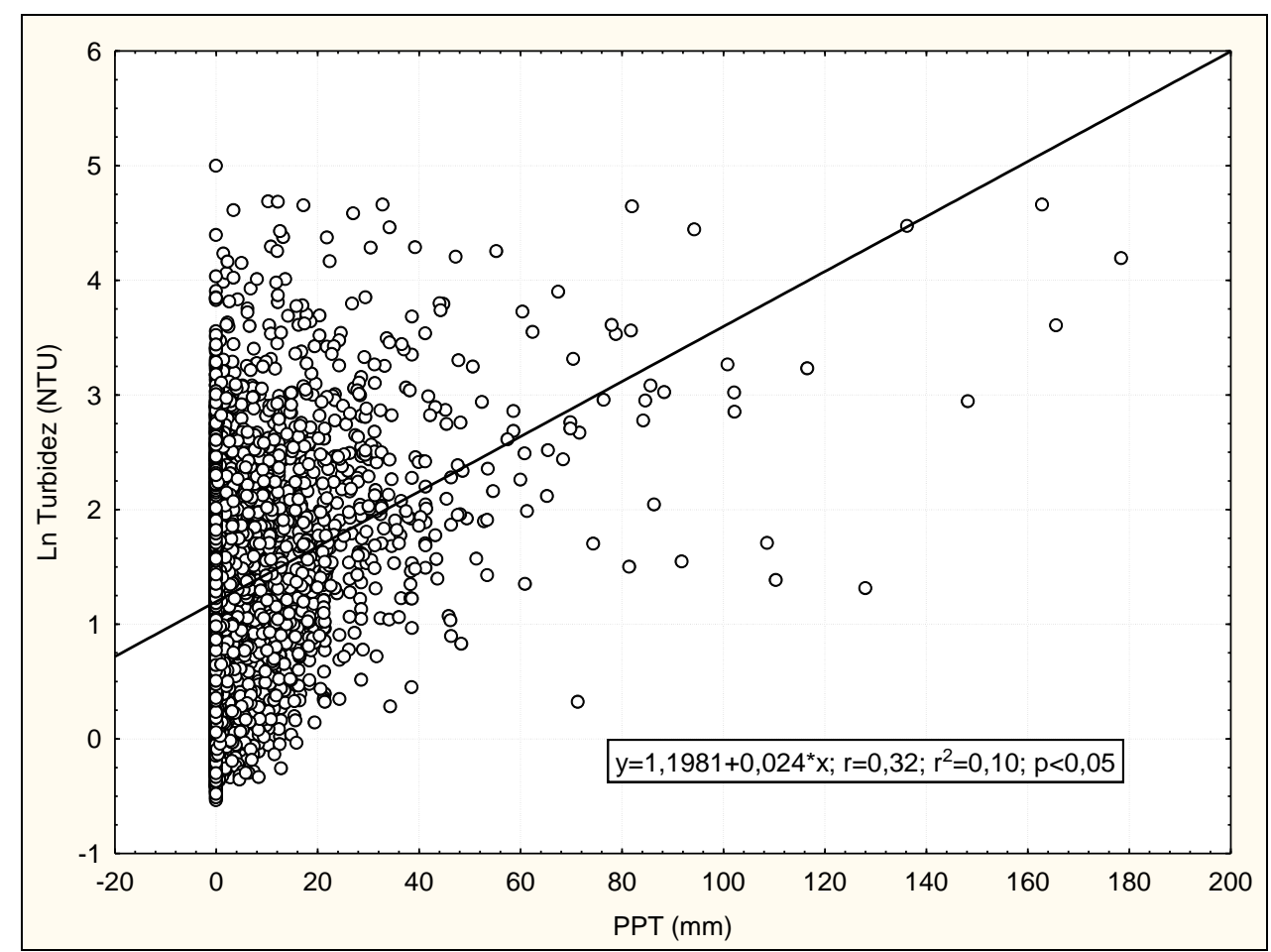

Fonte: Elaborado pelas autoras.

Observa-se que a maior influência na variação da turbidez provocada pela precipitação é conferida após um dia da observação do evento meteorológico. Também se observa que quando a precipitação é maior que $35 \mathrm{~mm}$ no período de 24h, aumenta o poder de explicação da precipitação sobre a turbidez, quando esta explica quase $20 \%$ da variação da turbidez $\left(R^{2}=0,19 ; p<0,05\right)$ (Figura 05$)$. Entretanto a explicação deste fenômeno sobre a turbidez é muito baixa, não sendo um bom preditor para a mesma e sugerindo que a variação das partículas em suspensão é explicada por outros fatores além da ocorrência de chuvas. 
Figura 05 - Variação da Turbidez (NTU) em função da Precipitação (mm) na mistura da água dos rios, antes da entrada na ETA José Pedro Horstmann, quando considera-se valores de precipitação maiores que $35 \mathrm{~mm}$ registrados no período de um dia( $R 2=0,19$; $\mathrm{p}<0,05)$

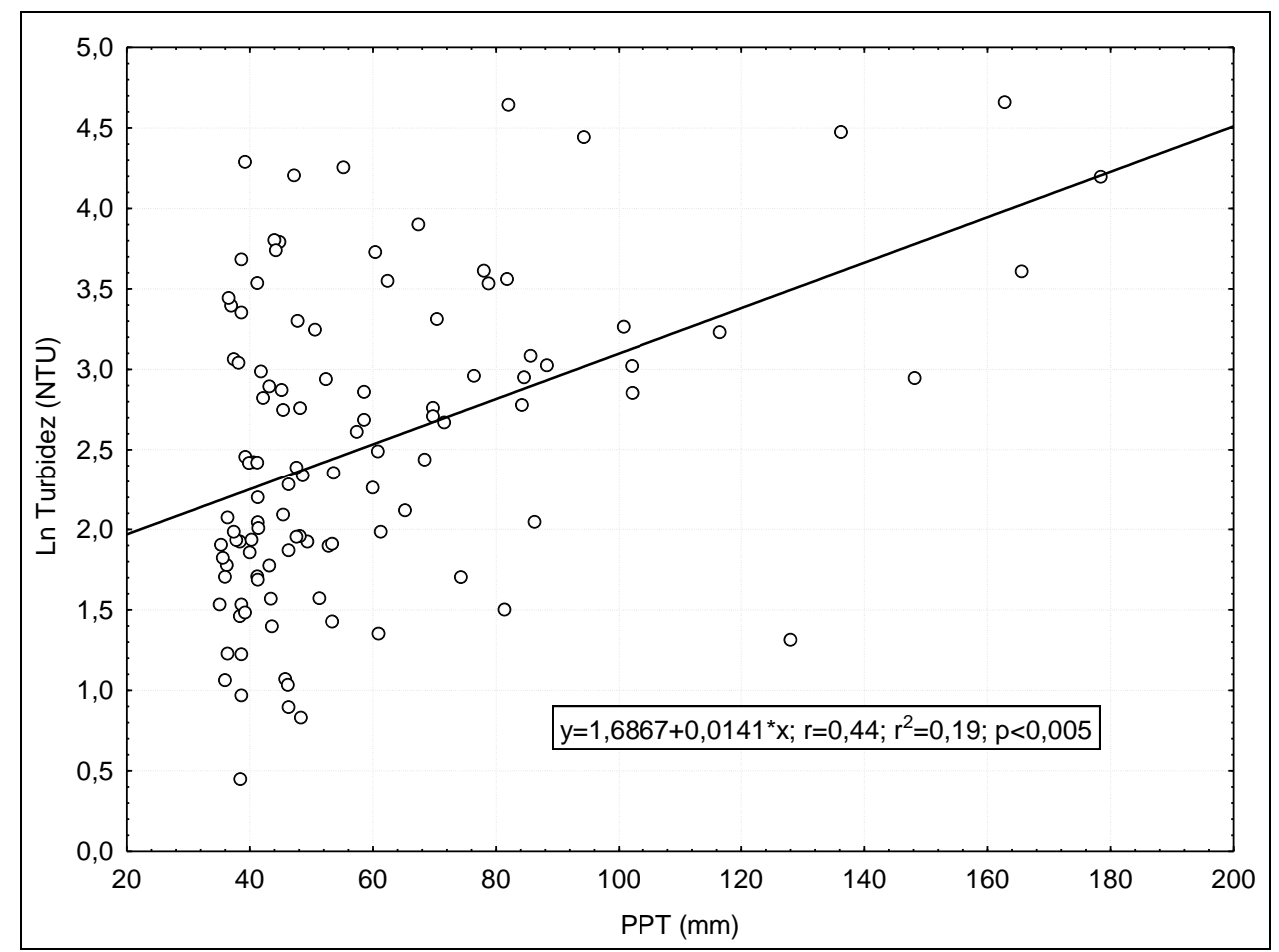

Fonte: Elaborado pelas autoras.

Um dos fatores que pode interferir nos resultados da relação de precipitação e turbidez é o balanço hídrico da bacia e deve-se levar em consideração que grande parte da bacia hidrográfica do rio Cubatão do Sul está inserida dentro do Parque Estadual da Serra do Tabuleiro - PEST - que tem função de extrema importância na preservação dessas áreas.

De acordo com Freitas (2016) o PEST é a maior unidade de conservação de proteção integral do Estado de Santa Catarina, ocupando aproximadamente 1\% do território catarinense (antes de 2009, cerca de 90.000 ha e atualmente 84.130 ha) e abrangendo áreas dos municípios de Florianópolis, Palhoça, Santo Amaro da Imperatriz, Águas Mornas, São Bonifácio, São Martinho, Imaruí e Paulo Lopes.

O PEST foi criado pelo Decreto 1.260, em 1975, abrangendo terras ocupadas por diversos grupos, mas não foi regularizado e, em 1993, a UNESCO estabeleceu a Reserva da Biosfera da Mata Atlântica em Santa Catarina, incluindo o PEST como sua Zona Núcleo. Em 2009, seus limites foram reavaliados e definidos pela Lei 14.661, que instituiu o Mosaico de Unidades de 26 Conservação da Serra do Tabuleiro e Terras de Massiambu, ou seja, desanexou grandes proporções do Parque e as transformou em APA (Área de Proteção Ambiental), dentre as quais a área da Vargem do Braço, tornando legal a presença dos grupos humanos que aí já habitavam. Essa lei ficou conhecida como lei da "recategorização" e sua promulgação se deu em meio a um contexto de discussão pública conflituoso. O processo que levou a sua aprovação foi considerado ilegítimo 
e contestado por diversas partes que constituíam o debate sobre possíveis soluções para os impasses na implementação da UC, que já duravam 34 anos. A própria agência ambiental do Estado, a FATMA, havia se posicionado contra a proposta do Movimento pela Recategorização, que foi, posteriormente, "vencedora". Porém, passados seis anos da mudança na lei, a situação da Vargem do Braço continua sendo de indefinição quanto às regras de uso do solo, já que o plano de manejo não foi elaborado e o conselho gestor funcionou por apenas 10 meses, desde então. Não houve andamento no processo de indenização pela perda de parte das propriedades, diante dos novos limites do Parque, além do que o andamento dos trabalhos do conselho gestor da APA foram interrompidos, diante de um impasse entre o entendimento dos representantes dos moradores locais no conselho e representantes do poder público, em relação à votação do plano de manejo elaborado por uma empresa contratada pela comunidade (FREITAS, 2016).

Estes conflitos se estendem desde a criação do parque e não deixam claras as atividades possíveis nessas áreas, o que prejudica a população atingida pelo PEST e também a biodiversidade que precisa de proteção. Esse é um fator que tem influência direta na qualidade águas dos rios aqui estudados, tendo em vista que, as atividades presentes nas áreas da bacia hidrográfica alteram significativamente 0 balanço hídrico da região.

Parte da precipitação, entretanto, não participa do ciclo hidrológico na escala da bacia hidrográfica, sendo interceptada pela cobertura vegetal e retornando à atmosfera por evaporação. A depender da formação vegetal, o processo de interceptação pode suprimir entre 10\% e 30\% da água precipitada, e o restante atinge a superfície diretamente ou por meio do espaço entre a cobertura vegetal e pelos troncos das plantas. Algumas florestas têm diferentes estratos arbóreos e arbustivos que interceptam novamente a água liberadas pela cobertura vegetal superior, intensificando ainda mais o processo. A interceptação é mais efetiva nas chuvas de fraca intensidade, que favorecem a retenção e a evaporação da água, do que nas precipitações mais intensas. (STEVAUX e LATRUBESSE, 2017).

Sergio (2012) analisa a estimativa do balanço hídrico para a bacia hidrográfica do rio Cubatão do Sul, e conclui que apresenta um total de precipitação anual de $1872,8 \mathrm{~mm}$. Desse valor, 47,2\% são evapotranspirados e 50,6\% são convertidos em escoamento total. Apenas $2,2 \%$ são armazenados no solo e fazem a recarga do aquífero profundo. Ou seja, a parte de precipitação que é evapotranspirada ou absorvida pelo solo não influencia na turbidez das águas, visto que, não ocorre o escoamento superficial.

Em relação ao balanço hídrico, Penedo (2015) fala que a precipitação que atinge o solo irá converter-se em infiltração ou escoamento superficial, de acordo com as características do solo, do seu uso e da conformação do terreno.

Quando a intensidade de precipitação excede a capacidade de infiltração do solo, a água da chuva é acumulada primeiramente nas microdepressões da superfície, para posteriormente dar início ao escoamento superficial não concentrado, uma vez que não há condições suficientes para a incisão de 
um canal. Esse escoamento ocorre por meio de um fluxo laminar chamado de fluxo hortoniano (STEVAUX e LATRUBESSE, 2017).

Segundo Tucci (2007), o escoamento superficial é a parcela do ciclo hidrológico em que a água se desloca na superfície até encontrar uma calha definida. Penedo (2015) menciona que o escoamento superficial é influenciado pela precipitação, relevo, cobertura vegetal, estradas, áreas edificadas e impermeáveis. Da mesma forma que ocorre com a infiltração, a quantidade de água disponível é fator determinante na dinâmica do escoamento superficial, que tende a crescer com o aumento da intensidade e duração da precipitação.

Stevaux e Latrubesse (2017) ainda mencionam que sob uma mesma precipitação, litologia e relevo, uma bacia florestada produzirá um escoamento final muito inferior ao de uma bacia com qualquer outra cobertura vegetal. Isso se dá devido à grande quantidade de água que uma floresta consome sob a forma de evapotranspiração e à alta taxa de infiltração propiciada pela resistência física ao fluxo superficial.

\section{Erosão e extração de areia}

Com relação às extrações de areia, que causam erosão na bacia hidrográfica, Stevaux e Latrubesse (2017) falam que, a erosão superficial é controlada por clima (duração e intensidade da precipitação), litologia e manto de intemperismo (capacidade de infiltração e natureza das partículas), topografia (declividade e comprimento da vertente), cobertura vegetal (tipo e densidade) e uso do solo (solo descoberto, tipo de plantação, impermeabilização).

Como já vimos, o rio principal tem no seu início de percurso, uma inclinação maior do que a no final de percurso. Essa inclinação elevada coincide com as áreas mais preservadas da bacia, o que diminui a chegada dos pingos de chuva diretamente no solo diminuindo a erosão. De acordo com Sacramento (2015) a erosão causa o desprendimento de partículas minerais, denominadas sedimentos, e juntamente com as águas pluviais, vão em direção ao corpo hídrico. As partículas sólidas em suspensão causam turbidez, conferindo à água um aspecto turvo e impedindo que a luz alcance partes mais baixas. No abastecimento público a turbidez causa o aumento do custo do tratamento da água, uma vez que quanto mais sedimentos a água possuir, maior o custo com a utilização de produtos químicos para a remoção destas partículas. 
Neste contexto, considera-se que as dragagens tem impacto significativo nas águas da bacia hidrográfica do rio Cubatão do Sul. Segundo Stevaux e Latrubesse (2017) a dragagem consiste na remoção de sedimento do fundo do canal, geralmente para o aumento de sua capacidade, seja para ampliar o escoamento do fluxo de cheia, seja para viabilizar a navegação. Ela também é empregada na mineração dos depósitos aluviais (areia e cascalho) do fundo do canal.

Os processos que removem e transportam o material da crosta terrestre são chamados genericamente de erosão ou denudação. De modo geral, os estudos de erosão fluvial estão intimamente relacionados aos processos de transporte e sedimentação, uma vez que esses fenômenos ocorrem simultaneamente, ainda que variando de intensidade, ao longo do canal de um rio. A remoção do material se dá basicamente de duas formas: erosão química, na qual o material é dissolvido e transportado sob a forma de solução iônica, como a carga dissolvida; erosão física, pela retirada de fragmentos de tamanhos variados do solo ou da rocha e que adentram o sistema sob a forma de carga sedimentar. (STEVAUX e LATRUBESSE, 2017).

Sobre extração de areia Sacramento (2015) analisou o trabalho feito por Thomas e Gomes (2005) e verificou que existem essencialmente três tipos de extração de areia: Extração em leito de rio; Extração em cava submersa e Desmonte hidráulico de solos residuais.

Para Sacramento (2015) é certa a degradação ambiental que as extrações de areia causam ao meio ambiente e o rio Cubatão do Sul não seria exceção. 0 aumento do aporte de sedimentos advindos destas atividades contribuiu para uma maior turbidez e intensificação no processo de assoreamento ao longo do seu curso. Na Figura 06 estão localizados pontos de extração de areia na área de estudo.

Figura 06 - Localização de pontos de extração de areia no rio Cubatão do Sul

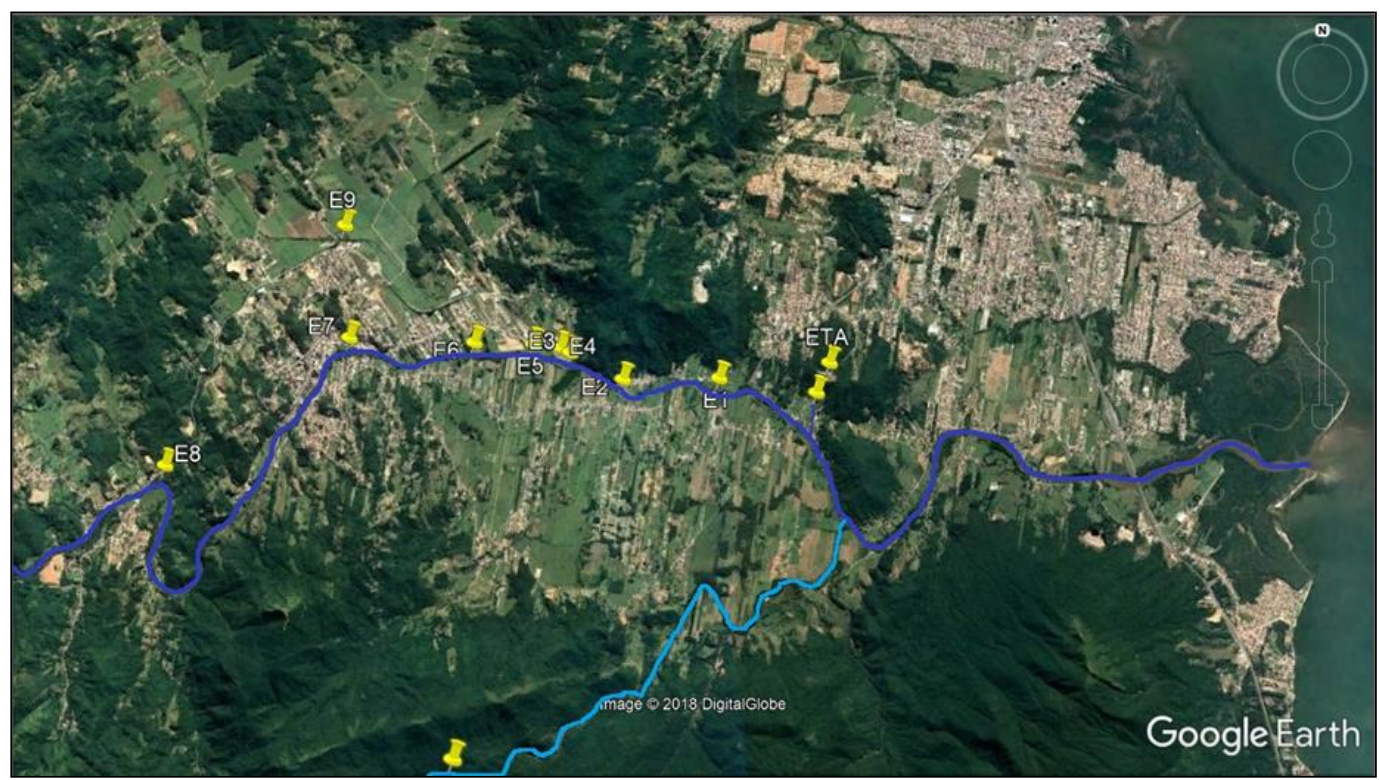

Fonte: Google Earth, 2018. 
$\mathrm{Na}$ imagem pode-se observar o rio Cubatão do Sul em azul escuro e o rio Vargem do Braço em azul claro. Foram localizados oito pontos de extração de areia no rio Cubatão do Sul a jusante da captação da ETA. Os pontos com extrações de areia estão identificados da seguinte forma: E1, E2, E3, E4, E5, E6, E7, E8. O ponto E9 está localizado no afluente, o rio Matias.

Na Figura 07 é apresentada uma imagem de satélite detalhando a região onde são encontradas extrações de areia em pontos próximos.

Figura 07 - Detalhe das águas do rio Cubatão do Sul próximo às extrações de areia

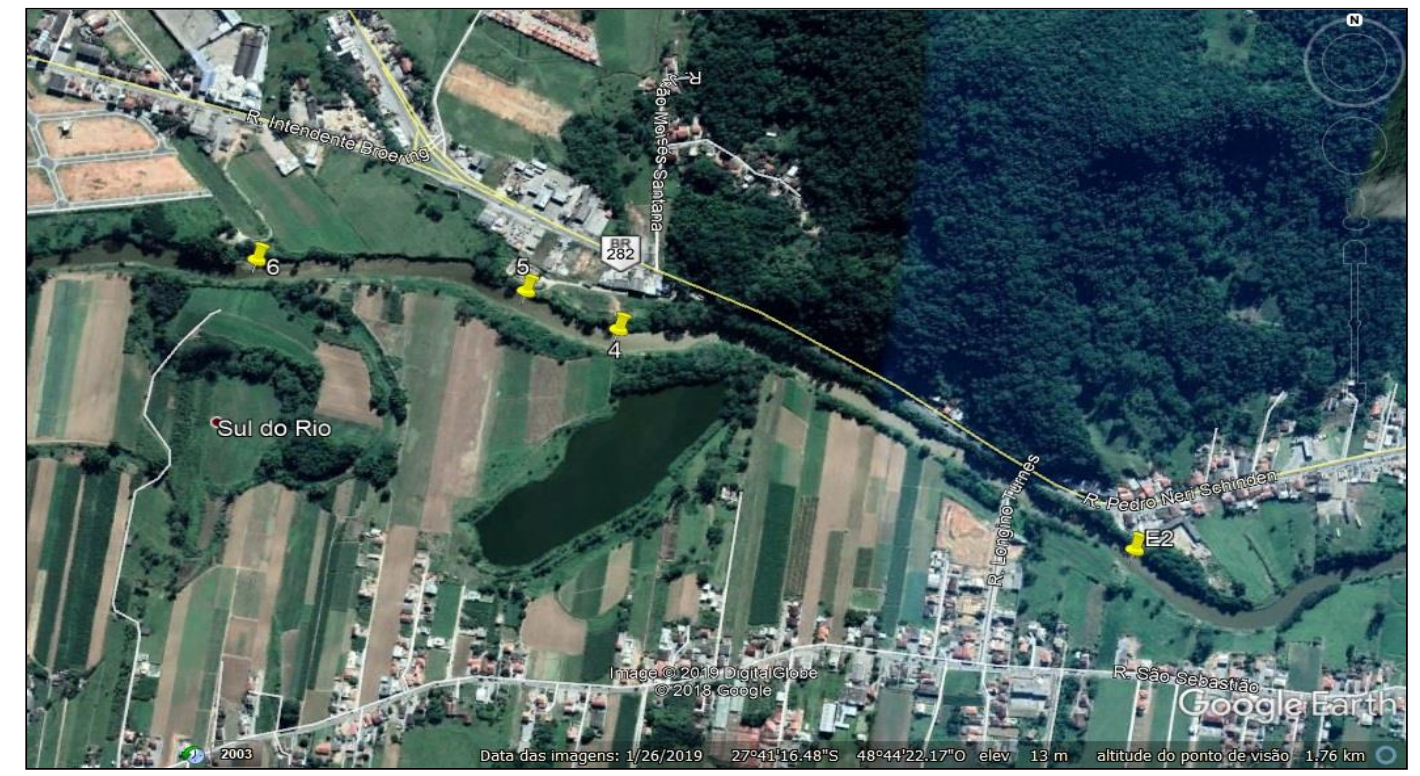

Fonte: Google Earth, 2019.

No detalhe da imagem, nas extrações numeradas E4, E5 e E6, no município de Santo Amaro da Imperatriz, observa-se uma alteração significativa na "coloração" da água após a passagem pelas áreas de extração de areia.

Sacramento (2015) fala que o tipo de extração utilizado no Rio Cubatão do Sul é do tipo extração em leito de rios (ou dragagem), e ela consiste no bombeamento de areia que se encontra no fundo do curso d'água, utilizando a água como meio de transporte. A massa formada pela água e areia é chamada de polpa, possuindo uma razão média de 60/40 destas substâncias, respectivamente. A água presente nesta massa é praticamente toda devolvida ao rio, sendo que a areia permanece na draga. Porém, a água devolvida possui sedimentos finos, responsáveis pelo aumento da turbidez. Segundo os autores, a concentração de sedimentos encontrada no lançamento desta água devolvida (considerada como efluente) é bastante complexa de ser quantificada, necessitando de medições de sedimentos antes e depois dos locais onde ocorrem as extrações para tentar fazer essa analise. 
Fundamentalmente, dois tipos de mineração ocorrem nos canais fluviais: a extração direta do material (areia e cascalho) do fundo do canal ou dos depósitos da margem e a mineração de bens minerais associados aos depósitos aluviais. Cerca de $90 \%$ da areia produzida no Brasil é de origem fluvial, sendo mais da metade desse valor destinada à construção civil. $\mathrm{O}$ processo de extração de areia é muito semelhante ao de dragagem: a draga bombeia a areia e outros sedimentos que estão depositados no fundo do rio utilizando a própria água como veículo. A mistura de areia e água bombeada, denominada polpa, contem normalmente uma proporção de $60 \%$ de água e $40 \%$ areia. A areia bombeada fica depositada na draga e a água retorna ao rio juntamente com os sedimentos finos. O volume se água bombeado pela draga é praticamente todo devolvido ao rio, com exceção de uma pequena parcela que fica agregada à areia. (STEVAUX e LATRUBESSE, 2017)

O Mapa de Produção Mineral do Estado de Santa Catarina (2013), confirma a existência de extrações de areia na área da Bacia Hidrográfica do rio Cubatão do Sul. Conforme a Figura 08 - recorte do mapa de produção mineral de SC observam-se oito pontos de extração de areia na área do rio Cubatão do Sul, sendo a maioria de minas de porte micro a pequenas ( $<10.000$ a 100.00 ton/ano). Além da extração de areia existem minas de brita e cascalho, saibro e água mineral.

Figura 08 - Recorte do Mapa de Produção Mineral de Santa Catarina, com destaque para áreas próximas ao leito do rio Cubatão do Sul

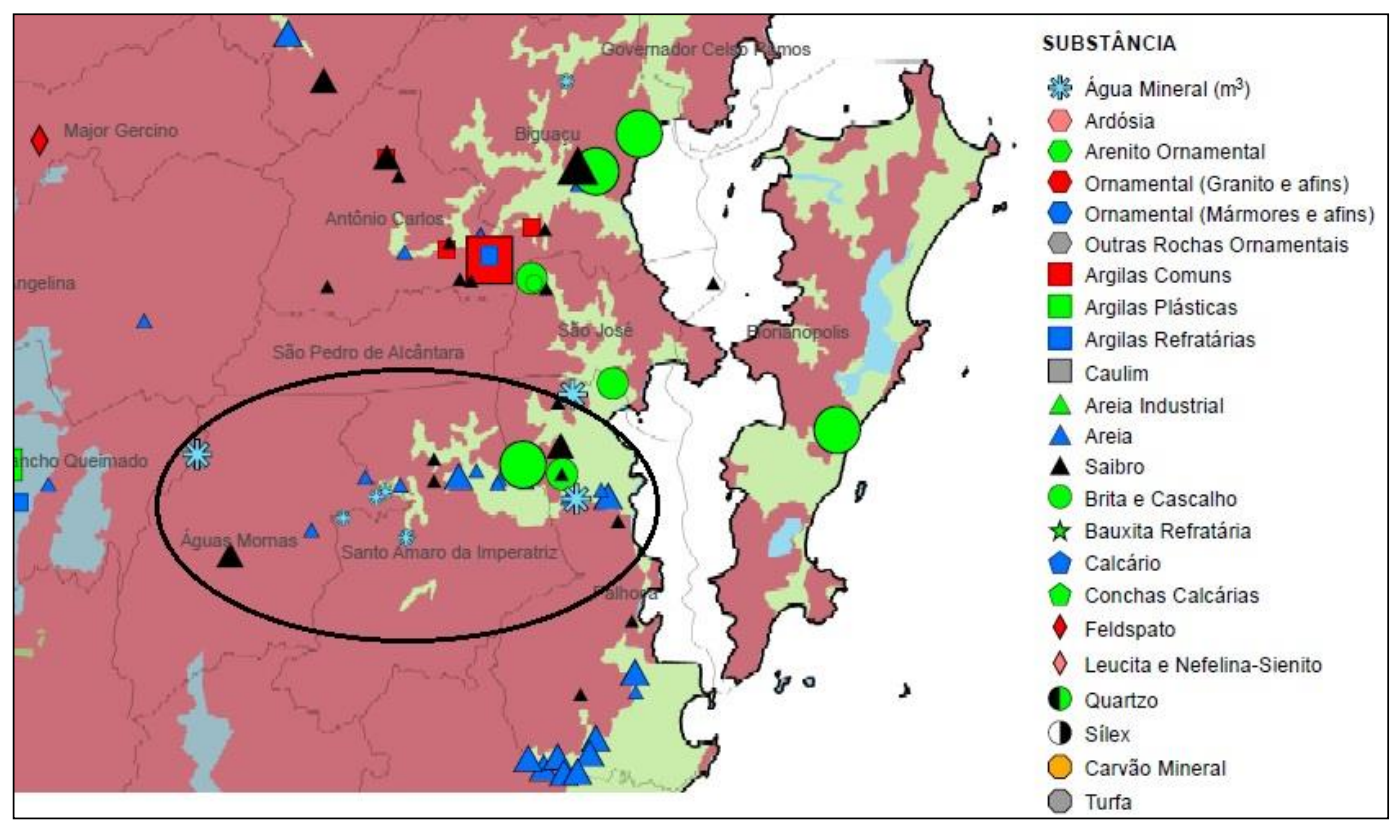

Fonte: DNPM, 2013.

De acordo com DNPM (2017) a produção beneficiada de areia, no Estado de Santa Catarina, em 2014 foi de 168 milhões de toneladas, em 2015 foi de 223 milhões de toneladas e em 2016 foi de 180 milhões de toneladas. Se tratando do valor da produção mineral comercializada, em reais $(R \$)$, segue Tabela $01 \mathrm{com} o$ histórico: 
Tabela 01 - Valor da produção mineral comercializada de areia em Santa Cataria

\begin{tabular}{|c|c|}
\hline Ano & $\begin{array}{c}\text { Valor } \\
\text { (milhões de } \\
\text { reais R\$) }\end{array}$ \\
\hline 2010 & 58 \\
\hline 2011 & 69 \\
\hline 2012 & 80 \\
\hline 2013 & 96 \\
\hline 2014 & 98 \\
\hline 2015 & 100 \\
\hline 2016 & 97 \\
\hline
\end{tabular}

Fonte: DNPM, 2017.

Percebe-se aumento do valor produzido ano a ano, com uma pequena queda em 2016. A produção de areia das minas legalizadas em Santo Amaro da Imperatriz e Palhoça giram em torno de 60.000 toneladas ano, valor que vem caindo desde a crise que atingiu o setor da construção civil.

Segundo o DNPM (2017) em relação ao mercado consumidor da areia extraída e beneficiada em Santa Catarina 55,49\% são destinadas para argamassa para a construção civil, 44,49\% são para a construção civil diretamente e apenas 0,02\% são destinadas a aterro. Já em se tratando de distribuição geográfica da areia extraída e beneficiada, o mercado consumidor de Santa Catarina fica com 88,35\%, o Rio Grande do Sul com 9,54\% e o Estado do Paraná com 2,12\% da areia.

A atividade extração de areia está regulamentada pela Lei Federal no $6.567 / 1974$ que estabelece as normas para o licenciamento, pelo Decreto Federal $\mathrm{n}^{\circ}$ 97.632/89 que exige para todos os empreendimentos de extração mineral em operação no país, a apresentação do Plano de Recuperação de Áreas Degradadas (PRAD) e pela resolução no 24/2013 do Conselho Estadual de Meio Ambiente (CONSEMA) do Estado de Santa Catarina (SC). Ao licenciamento e fiscalização da atividade cabe ao órgão ambiental do Estado, no caso de SC a Fundação de Meio Ambiente (FATMA), atualmente reestruturado como Instituto do Meio Ambiente (IMA) (HORSTMANN, 2014).

De acordo com Horstmann (2014) no município de Santo Amaro da Imperatriz não existe nenhuma legislação que trate do licenciamento deste tipo de atividade, apenas para o equipamento utilizado para extração. Conforme a Lei Municipal no 2.273/2013 "fica proibida a utilização de desagregadores (maracas) na base territorial do Município de Santo Amaro da Imperatriz".

Segundo Sacramento (2015) a bacia do rio Cubatão do Sul vem sofrendo com o aumento do aporte de sedimentos, advindos do mau uso do solo e também de atividades mineradoras que ocorrem ao longo do rio Cubatão. Um dos grandes 
impactos observados na região foi a alta da turbidez ao longo do tempo. Na década de 1980, o rio Cubatão apresentava pouca turbidez, permanecendo neste estado até mesmo em períodos de chuva. O cenário atual já não é mais o mesmo, seu curso d'água apresenta valores elevados de turbidez mesmo quando não chove.

Horstmann (2014) conclui que a mineração irregular, que altera as características tanto das margens (quando a areia é retirada nas mesmas) como da mata ciliar, juntamente com os efeitos produzidos pela presença dos agentes antrópicos vêm degradando sistematicamente o rio Cubatão do Sul. Ainda segundo Horstmann (2014) a causa para os problemas enfrentados no tratamento da água na ETA José Pedro Horstmann, pode estar principalmente na realização da atividade de mineração de areia no leito do rio, por ter como consequência uma elevação significativa nos parâmetros de cor e turbidez pelo processo de extração utilizado, bem como pelo efluente gerado devido a lavagem inadequada da areia extraída.

Todas as atividades presentes na bacia hidrográfica causam impactos na qualidade da mistura das águas que chegam na ETA para tratamento.

\section{Considerações finais}

Existe uma tendência de aumento da precipitação e um aumento da turbidez na bacia hidrográfica nos meses de verão, contudo a precipitação não explica a variação da turbidez. Na série histórica analisada observou-se que não existe uma relação significativa entre a precipitação ocorrida na bacia hidrográfica do rio Cubatão do Sul e a turbidez da água recebida na ETA José Pedro Horstmann. A partir do estudo, foi verificado que a precipitação explica apenas $10 \%$ da turbidez das águas da bacia hidrográfica e que o seu maior efeito ocorre um dia após o evento climático.

Existem outros fatores que interferem na variação da turbidez, como as áreas do Parque Estadual da Serra do Tabuleiro, onde as matas ciliares preservadas absorvem parte do escoamento superficial, regulando a turbidez. A atividade realizada na bacia hidrográfica do rio Cubatão do Sul, que tem impactos mais significativos na qualidade da água recebida para tratamento na ETA José Pedro Horstmann, é a extração de areia para a construção civil, pois eleva a turbidez do manancial aumentando os custos do tratamento para potabilizar a água. Além disso, causa demanda maior de produtos químicos, que também tem impactos para toda a população que recebe esta água. 
De maneira geral, as atividades desenvolvidas no manancial acabam interferindo na preservação da qualidade da água realizada pelo Parque Estadual da Serra do Tabuleiro, uma vez que, antes de chegar à ETA José Pedro Horstmann a água é deteriorada pelas atividades antrópicas.

\section{REFERÊNCIAS}

ANA. Agencia Nacional das Águas. Portal da qualidade das águas. Disponível em: < http://portalpnqa.ana.gov.br/indicadores-indice-aguas.aspx\#_ftn8>. Acesso em 20 de fevereiro de 2018.

BRASIL. Departamento Nacional de Produção Mineral. Anuário Mineral Estadual - Santa Catarina / Coord. Técnica de Lia Fernandes et al.; Equipe Técnica por Júlio César Recuero; Fábio Larroyd; César Veronez. - Brasília: DNPM, 2017.

CASAN - Companhia Catarinense de Águas e Saneamento. Mananciais Casan Expedição ao Rio Cubatão. 2003. Disponível em: <https://www.casan.com.br/menuconteudo/index/url/expedicao-ao-rio-cubatao\#0> Acesso em 24 de abril de 2019.

CASAN. Companhia Catarinense de Águas e Saneamento. Superintendência Região Metropolitana da Grande Florianópolis. Plano de emergência para o sistema de abastecimento de água de Florianópolis - SIA integrado da Grande Florianópolis. 2013. Disponível em: < <http://aresc.sc.gov.br/index.php/documentos/planoemergencial/plano-emergencial-agua/plano-de-emergencia-2013/529-sia-integrado-

florianopolis-externo-2013/file>. Acesso em 24 de abril de 2019.

CURTARELLI, M. P. SIG aplicado à caracterização morfométrica de bacias hidrográficas - estudo de caso da bacia hidrográfica do rio Cubatão do Sul - Santa Catarina/Brasil. Anais XIV Simpósio Brasileiro de Sensoriamento Remoto, Natal, Brasil, 2530 abril 2009, INPE, p. 4693-4699. Disponível em: <http://www.gthidro.ufsc.br/arquivos/4693-4699.pdf> Acesso em 24 de abril de 2019.

DELPLA, A.-V. Jung, E. Baures, M. Clement, O. Thomas. Impacts of climate change on surface water quality in relation to drinking water production. Environment International. (2009) 1225-1233. Disponível em: <https://www.sciencedirect.com/science/article/pii/S0160412009001494\#! > 25 de abril de 2019.

DIAS, M. A. F. S. As chuvas de novembro de 2008 em Santa Catarina: Um estudo de caso visando à melhoria do monitoramento e da previsão de eventos extremos. São José dos Campos: INPE, 2009. Disponível em: <http://intranetdoc.epagri.sc.gov.br/producao_tecnico_cientifica/DOC_3661.pdf>Acesso em 25 de abril de 2019.

EXTERCKOTER, R. K. Diagnóstico Da Qualidade Das Relações Ambientais Estabelecidas No Uso Da Água Na Bacia Hidrográfica Do Rio Cubatão Do Sul (SC). Dissertação do Programa de Pós-Graduação em Agroecossistemas, Centro de Ciências Agrárias, Universidade Federal de Santa Catarina. 2006. Disponível em: <https://repositorio.ufsc.br/handle/123456789/88481?show=full> Acesso em 24 de abril de 2019. 
Freitas, P. B. Serra do Tabuleiro, histórias de um "não-parque": análise dos conflitos na trajetória de uma unidade de conservação de Santa Catarina. Tese (doutorado) Universidade Federal de Santa Catarina, Centro de Filosofia e Ciências Humanas, Programa de Pós-Graduação em Sociologia Política, Florianópolis, 2016. Disponível em: <https://repositorio.ufsc.br/handle/123456789/172355> Acesso em 25 de abril de 2019.

GONÇALVES, J. C. S. I.;SARDINHA, D. S.; SOUZA, A. D. G.; DIBIAZI, A. L. B.; GODOY, L. H.; CONCEIÇÃO, F. T. Avaliação espaço-temporal da qualidade da água e simulação de autodepuração na bacia hidrográfica do córrego São Simão, SP. Ambi-Agua, Taubaté, v. 7, n. 3, p. 141-154, 2012. Disponível em: $<$ https://repositorio.unesp.br/bitstream/handle/11449/114537/S1980-

993X2012000300012.pdf?sequence=1\&isAllowed=y> Acesso em 25 de abril de 2019.

GOTARDO, R. et al. Distribuição espacial e temporal das chuvas no estado de Santa Catarina. Geosul, Florianópolis, v. 33, n. 67, p. 253-276, mai./ago. 2018. Disponível em: <https://periodicos.ufsc.br/index.php/geosul/article/view/2177-5230.2018v33n67p253>

Acesso em 25 de abril de 2019.

HORSTMANN R. J. Filho. Avaliação da qualidade da água do rio Cubatão do Sul e os prejuízos que atividades antrópicas representam para o tratamento da água de abastecimento. Trabalho de Conclusão de Curso. UNISUL. Palhoça, 2014. Disponível em: <https://www.riuni.unisul.br/handle/12345/1408> Acesso em 24 de abril de 2014.

LARROYD, F.; RECUERO, J. C. Mapa da Produção Mineral De Santa Catarina. Ano base 2013. Florianópolis: DNPM, 2017. Disponível em: <http://www.anm.gov.br/dnpm/paginas/anuario-mineral-estadual/sc20082013/view> Acesso em 25 de abril de 2019.

PENEDO, P. H. S. Relação entre precipitação e turbidez em cursos d'água no Espírito Santo. 2015. Dissertação de Mestrado em Ciências Florestais - Universidade Federal do Espírito Santo, Alegre - ES. Disponível em: <http://repositorio.ufes.br/handle/10/5073> Acesso em 25 de abril de 2019.

PEREIRA, M. A. F.; KOBIYAMA, M.; Análise de variâncias pluviométricas na região da bacia hidrográfica do Cubatão do Sul (SC). Ambiência Guarapuava (PR) v.9 n.1 p. 95 111 Jan./Abr. 2013. Disponível em: <https://revistas.unicentro.br/index.php/ambiencia/article/view/1709> Acesso em 24 de abril de 2019.

RAPOSO, A.A.; BARROS, L.F.P.; MAGALHÃES JÚNIOR, A.P.M. (2009). O parâmetro de turbidez das águas como indicador de impactos humanos na dinâmica fluvial da bacia do rio maracujá- Quadrilátero Ferrífero/MG. In: XIII Simpósio Brasileiro de Geografia Física Aplicada. Viçosa. UFV. Disponível em: <http://www.geomorfologia.ufv.br/simposio/simposio/trabalhos/trabalhos_completos/eixo3/00 7.pdf> Acesso em 25 de abril de 2019.

SACRAMENTO, D. L. P. Utilização de ferramentas de gestão ambiental para a melhoria da qualidade do rio Cubatão (Santa Catarina). Universidade Federal de Santa Catarina UFSC. Trabalho de Conclusão de Curso. Curso de Graduação em Engenharia Sanitária e Ambiental. 2015. Disponível em: <https://repositorio.ufsc.br/handle/123456789/160025> Acesso em 24 de abril de 2019.

SANTA CATARINA, Governo do Estado de. Bacia do Cubatão Sul. Secretaria de Estado do Desenvolvimento Econômico Sustentável. Diretora de Recursos Hídricos. SDS/DRHI, $2010 . \quad$ Disponível em: < http://www.sirhesc.sds.sc.gov.br/sirhsc/baixararquivo.jsp?id=460\&NomeArquivo=Mapa\%20B ase\%20-\%20Cubata0\%20Sul.pdf> Acesso em 04 de junho de 2019. 
SERGIO, D. Z. Modelagem hidrológica da bacia do rio Cubatão do Sul com modelo Swat. TCC (graduação) - Universidade Federal de Santa Catarina. Centro Tecnológico. Engenharia Sanitária e Ambiental. 2012. Disponível em: <https://repositorio.ufsc.br/handle/123456789/125090> Acesso em 25 de abril de 2019.

STEVAUX, J. C; LATRUBESSE, E. SC, Estado de Santa Catarina. Água - recurso para manutenção da vida. 2013. Geomorfologia fluvial. São Paulo: Oficina de Textos, 2017.

THOMAS, P; GOMES, P. Mecanismos de Cobrança pelo Uso de Recursos Hídricos para o Setor de Extração de Areia da Bacia Hidrográfica do Rio Paraíba do Sul. 2005. Disponível em: <http://arquivos.ana.gov.br/institucional/sag/CobrancaUso/BaciaPBS/Textos/Cobranca\%20E xtracao\%20de\%20Areia\%20-\%20Patrick\%20-\%20nov05\%20-\%20Artigo.pdf> Acesso em 25 de abril de 2019.

TUCCI, C. E. M. Escoamento superficial. In: TUCCI, C. E. M. (Org.). Hidrologia: ciência e aplicação. Porto Alegre: Editora UFRGS, 2007.

\section{NOTAS DE AUTOR}

\section{CONTRIBUIÇÃO DE AUTORIA}

Juliana Loch - Concepção, Investigação, Coleta de dados, Análise de dados, Elaboração do manuscrito, revisão.

Débora Monteiro Brentano - Orientação, Participação ativa na elaboração e discussão dos resultados, Revisão e aprovação da versão final do trabalho.

\section{FINANCIAMENTO}

UNIEDU - Programa de Bolsas Universitárias de Santa Catarina.

\section{CONSENTIMENTO DE USO DE IMAGEM}

Não se aplica.

\section{APROVAÇÃO DE COMITÊ DE ÉTICA EM PESQUISA}

Não se aplica.

\section{CONFLITO DE INTERESSES}

Não se aplica.

\section{LICENÇA DE USO}

Este artigo está licenciado sob a Licença Creative Commons CC-BY-NC. Com essa licença você pode compartilhar, adaptar, criar para qualquer fim, sem uso comercial e desde que atribua a autoria da obra.

\section{HISTÓRICO}

Recebido em: 06-06-2019

Aprovado em: 30-06-2020 